\title{
Inability of the ST segment/heart rate slope to predict accurately the severity of coronary artery disease
}

\author{
A A QUYYUMI, M J RAPHAEL, CHRISTINE WRIGHT, LORNA BEALING, K M FOX \\ From the National Heart Hospital, London
}

SUMMARY Analysis of the ST segment/heart rate slope during exercise testing has been suggested as a method of accurately predicting the presence and severity of coronary artery disease. Exercise tests were performed in 78 patients presenting with chest pain to determine the maximum ST segment/ heart rate slope. In $21(27 \%)$ patients the ST segment/heart rate slope could not be calculated in any electrocardiographic lead. In the remaining $57(73 \%)$ patients the maximum ST segment/heart rate slope accurately predicted the presence or absence of coronary disease in $\mathbf{4 4}$ patients (sensitivity $90 \%$, specificity $40 \%$ ). In addition, the extent of coronary disease was accurately predicted in 24 patients (sensitivity $42 \%$ ). Thus the maximum ST segment/heart rate slope did not perfectly predict either the presence or the severity of significant coronary artery disease.

Exercise testing is widely used in the diagnosis and management of patients with ischaemic heart disease. A rise in heart rate reflects increasing myocardial oxygen consumption with exercise, and ST segment depression occurs as myocardial ischaemia develops. Several studies have attempted to predict the extent of underlying coronary artery disease from the severity of ST segment depression but have been able to achieve no more than a rough correlation..$^{1-4}$ Recently, Elamin et al showed that a linear relation existed between the development of ST segment depression and increasing heart rate and that the maximum ST segment/heart rate (ST/HR) slope obtained during an exercise test was perfectly correlated with the extent of significant coronary disease. ${ }^{56}$ In view of the importance of such findings, we repeated exactly the exercise test described by Elamin et al in patients presenting with anginal chest pain and examined the relation between the ST segment/heart rate slope and coronary anatomy.

\section{Patients and methods}

STUDY POPULATION

Seventy eight patients (61 men and 17 women, aged

Requests for reprints to Dr A A Quyyumi, National Heart Hospital, Westmoreland Street, London WIM 8BA.

Accepted for publication 22 November 1983
35-78 years) undergoing diagnostic coronary angiography for the evaluation of chest pain were exercised. The patients were randomly selected non-consecutive admissions who were taking either beta blocking agents (41 patients) or no medication (37 patients) and were exercised according to the feasibility of performing the test. Patients who were currently taking nitrates, calcium antagonists, or digoxin were excluded as were those with a left ventricular aneurysm or uncontrolled hypertension, bundle branch block, or cardiac arrhythmias.

\section{EXERCISE TEST}

Exercise tests were performed identically to the criteria laid down by Elamin et al. ${ }^{56}$ The test was performed on a bicycle ergometer; the patients pedalled at a steady rate of $50 \mathrm{rpm}$, and the workload was increased every three minutes to achieve an increase in heart rate of approximately 10 beats $/ \mathrm{min}$ at each stage. A preliminary test was carried out to determine the workloads necessary to obtain an increase in the heart rate of 10 beats/min at each stage. The final test was performed after a suitable rest period when the heart rate had returned to baseline values. The test was terminated by anginal chest pain, significant ST segment depression $(\geqslant 0.3 \mathrm{mV})$, the development of multiple ventricular extrasystoles, a fall in blood pressure, or exhaustion.

A 12 lead electrocardiogram using the bipolar pre- 
cordial lead CM5 instead of lead aVR was recorded on an ink jet recorder (Siemens Mingocard 7). Recordings were made before and at the end of each stage of the submaximal exercise test, and blood pressure was measured at the end of each stage with a mercury sphygmomanometer. ST segment displacement was measured at a point $0.08 \mathrm{~s}$ after the end of the QRS complex, and the line drawn between two consecutive PR segments provided the zero baseline. These measurements were made using a magnifying lens equipped with a graticule marked in $0.1 \mathrm{~mm}$ divisions (Flubacher \& Co, Switzerland). A mean of the ST segment displacement over 10 beats and the mean heart rate (over 10 beats) were thus calculated.

The ST/HR slope was then calculated for each lead by determining the gradient of the regression line obtained from the final three points of the ST segment displacement against heart rate, provided that the correlation coefficient was statistically significant. The steepest ST/HR slope for each lead was then obtained by recruiting further points along the curve at submaximal exercise levels. The maximum ST/HR slope was then obtained from all the leads that were analysed and compared with the results of the coronary arteriogram. A number of electrocardiographic leads could not, however, be used to calculate the ST/HR slope, either because the resting ST segment displacement was $>0.05 \mathrm{mV}$ above the isoelectric line or because there was no depression of the ST segment below the baseline at the termination of the test.

\section{ANGIOCARDIOGRAPHY}

All patients who were exercised had selective coronary arteriography and left ventriculography performed within two months of the exercise test. Five views of the left coronary artery and two views of the right coronary artery were obtained in each patient. The angiograms were interpreted by a single consultant radiologist who was unaware of the results of the exercise test. Significant coronary artery disease was defined by Elamin $e t$ al as luminal narrowing of $\geqslant 75 \%$ in magnitude involving the first third of any three major coronary arteries. ${ }^{56}$ Left main stenosis was classified as two vessel disease. Coronary arteriograms were interpreted visually in those cases in which the lesions were unequivocally significant. Other lesions were measured to ensure narrowing of $\geqslant 75 \%$ in diameter before they were classified as being significant.

\section{Results}

In 21 of the 78 patients exercised the ST/HR slope could not be calculated as their electrocardiograms did not meet the criteria of Elamin et al. ${ }^{56}$ In 10 of these patients there was no ST segment segment
Table Maximal ST/HR slopes obtained in 57 patients with varying severity of coronary artery disease

\begin{tabular}{|c|c|c|c|c|}
\hline & \multicolumn{4}{|c|}{ Angiographic classification ${ }^{\star}$} \\
\hline & $N$ & $I V D$ & $2 V D$ & $3 V D$ \\
\hline $\begin{array}{l}\text { No of patients } \\
\text { Maximum ST/HR slope } \\
\quad(\mathrm{mm} . \text { beats } \\
\left.-1 . \text { min. } 10^{-3}\right)\end{array}$ & 15 & 16 & 15 & 11 \\
\hline $\begin{array}{l}\text { Range } \\
\text { Mean } \pm \text { SD } \\
\text { Range (Elamin et al) }\end{array}$ & $\begin{array}{l}5-37 \\
16 \pm 9 \\
3-11\end{array}$ & $\begin{array}{l}6-55 \\
25 \pm 20 \\
13-21\end{array}$ & $\begin{array}{l}9-91 \\
48 \pm 30 \\
32-59\end{array}$ & $\begin{array}{l}26-104 \\
69 \pm 31 \\
69-137\end{array}$ \\
\hline predicted & 6 & 7 & 4 & 7 \\
\hline
\end{tabular}

$\mathrm{N}$, no significant vessel disease; IVD, single vessel disease; $2 \mathrm{VD}$, double vessel disease; 3VD, triple vessel disease.

depression below the isoelectric line in any of the 12 electrocardiographic leads. In five patients the ST segment rose with increasing exercise in all the leads, and in three patients the ST segment in all the leads was $>0.5 \mathrm{~mm}$ above the baseline at rest. In a further three patients a significant slope could not be determined in any of the leads even though four or more stepwise increases in heart rate were obtained.

In 57 of the 60 patients in whom the ST/HR slope could be calculated there was a linear relation between the development of depression of the ST segment and increasing heart rate. A statistically significant correlation coefficient was obtained for the regression line between these two variables by using the final three or four points.

The results of the maximum ST/HR slopes in these 57 patients are shown in the Table. There was no correlation between the magnitude of the maximum ST/HR slope and the presence or absence of coronary artery disease and its severity. Although the maximum ST/HR slope tended to be higher in patients with more severe coronary artery disease, there was a considerable overlap between the ranges of slopes obtained in patients with varying severity of disease. In nine of the 15 patients without significant coronary disease ST/HR slopes were higher than the range found by Elamin et al..$^{6}$ In addition, eight of the 15 patients with one vessel disease, 11 of the 15 patients with two vessel disease, and four of the 11 patients with three vessel disease had maximum ST/HR slopes which did not correlate with the ranges set out by Elamin et al. 5

To exclude problems posed by learning a new technique we analysed the last 20 exercise tests separately. Five of these tests could not be analysed as they did not meet the electrocardiographic criteria required. 5 Two of the four patients with no significant disease, three of the four with one vessel disease, three of the four with two vessel disease, and one of the three with three vessel disease had ST/HR slopes which did not 
correlate with the ranges stated by Elamin et $a l^{56}$ and also showed a wide overlap as seen in the earlier exercise tests.

\section{Discussion}

We were unable to find a perfect relation between the maximum ST/HR slope and either the presence or the severity of coronary disease in a series of 78 patients. In $27 \%$ of our patients it was not possible to calculate the maximum ST/HR slope in any one of the 12 electrocardiographic leads. This finding is in direct contrast to those of Elamin et al, ${ }^{56}$ who were able to obtain maximum ST/HR slopes in a consecutive series of 206 patients. These exercise tests had to be excluded either because the ST segment was elevated $\geqslant 0.05 \mathrm{mV}$ above the baseline or, despite a linear depression of the ST segments with increasing heart rate, the ST segments did not depress below the isoelectric line at the end of the test. Finally, in some patients the ST segment in all the leads rose with exercise, but none of these patients had a left ventricular aneurysm at angiocardiography. Nevertheless, all these patients had technically satisfactory exercise tests which provided four or more stepwise increases in heart rate, and the termination heart rate in these patients varied from 90 to 165 (mean \pm SD $128 \pm 22$ ) beats/min.

Elamin et al did not specify a single end point for termination of the exercise tests, and they also stated that a 10 beat $/ \mathrm{min}$ increase in heart rate was desirable at each stage. Some patients had a very low exercise tolerance before they developed chest pain and significant ST segment depression, and this often occurred before the heart rate increased by more than 20 beats/min from the resting heart rate. Clearly, in such cases it was not possible to obtain three or more stepwise increases in heart rate of 10 beats $/ \mathrm{min}$. In these circumstances (six patients) the exercise tests were repeated to obtain stepwise increases of the heart rate of less than 10 beats $/ \mathrm{min}$. Exclusion of these patients from the analysis, however, did not alter the results.

The exercise test has so far been performed only on a bicycle ergometer using a high resolution mingograph recorder to abolish any excessive damping of the signals. Meticulous skin preparation is required to abolish any motion artefact that may occur, and a trial exercise test was performed by each patient to ensure an adequate increase in heart rate at each increment of workload. To obtain recording of sufficient technical quality so that further analysis could be made 15 exercise tests were performed during an initial learning period, the results of which were discarded from our final analysis. Separate analysis of the last 20 tests in our series did not change our findings, which suggests that the differences in our results are not due to problems posed by learning a new technique.

Reporting of coronary arteriograms is subject to both intraobserver and interobserver variability. ${ }^{78}$ For this reason alone it is perhaps somewhat surprising that a perfect correlation was obtained by Elamin et $a l^{5}$ between the radiographic appearances and the results of the exercise tests. We found it extremely difficult in several cases, for example, to be certain whether the narrowing in the coronary arteries was greater or less than $75 \%$, which determined the "significance" of the lesion. ${ }^{5}$ Although the coronary arteries were examined in several views a number of arteries appeared to have stenoses between $50 \%$ and $75 \%$, and in such cases measurements were made to determine the degree of narrowing. Even when patients in whom there were such difficulties in interpreting the angiograms were excluded, we had a number of cases with clearly normal coronary arteries or unequivocally diseased vessels in which ST/HR slopes did not correlate with the severity of coronary disease.

In conclusion, in this study every effort was made to reproduce the exercise test as described by Elamin $e t a l$, and, in addition, the angiograms were reported according to their criteria. In spite of this we were unable to reproduce their results. Furthermore, the maximum ST/HR slope could be calculated for only $73 \%$ of the patients who were exercised. We are unable to explain why our results differ so appreciably for those patients in whom the maximum ST/HR slope could be calculated. A non-invasive test to determine the severity of coronary disease in all patients would indeed have widespread use. This test, however, requires a large investment in both time and equipment, and unless a better correlation between ST/HR slope and coronary anatomy is obtained by workers in other centres, its widespread clinical use cannot be recommended at the present time.

We thank the British Heart Foundation for providing financial support.

\section{References}

1 Robertson D, Kostuk WJ, Ahuja SP. The localization of coronary artery stenosis by 12 lead ECG response to graded exercise test: support for intercoronary steal. Am Heart f 1976; 91: 437-44.

2 Ellestad MH, Cooke BM Jr, Greenberg PS. Stresstesting: clinical application and predictive capacity. Prog Cardiovasc Dis 1979; 21: 421-60.

3 McHenry PL, Phillips JF, Knoebel SB. Correlation of computer-quantitated treadmill exercise electrocardiogram with arteriographic location of coronary artery dis- 
ease. Am $\mathcal{F}$ Cardiol 1972; 30: 747-52.

4 Fox KM, Selwyn AP, Oakley D, Shillingford JP. Relation between the precordial projection of S-T segment changes after exercise and coronary angiographic findings. Am $\mathcal{F}$ Cardiol 1979; 44: 1068-75.

5 Elamin MS, Boyle R, Kardash MM, et al. Accurate detection of coronary heart disease by new exercise test. Br Heart f 1982; 48: 311-20.

6 Elamin MS, Mary DASG, Smith DR, Linden RJ. Pre- diction of severity of coronary artery disease using slope of submaximal ST segment/heart rate relationship. Cardiovasc Res 1980; 14: 681-91.

7 Zir LM, Miller SW, Dinsmore RE, Gilbert JP, Harthorne JW. Interobserver variability in coronary angiography. Circulation 1976; 53: 627-32.

8 Detre KM, Wright E, Murphy ML, Takaro TT. Observer agreement in evaluating coronary angiograms. Circulation 1975; 52: 979-86. 